\title{
Bronchial Anthracofibrosis and Tracheobronchomalacia
}

\author{
Mitra Samareh-Fekri, MD'; Seyed Mehdi Hashemi Bajgani, MD²; Ahmad Shafahi, MD²; Mohsen Shafiepour, MD²; Rostam Yazdani, \\ MD²; Mohammad Hossein Ahmadpour Baghdadabad, MD** \\ ${ }^{1}$ Cardiovascular Research Center, Basic and Clinical Institute of Physiology, Kerman University of Medical Sciences, Kerman, Iran \\ ${ }^{2}$ Afzalipour Hospital Research Center, Kerman University of Medical Sciences, Kerman, Iran
}

\begin{abstract}
Background: Tracheobronchomalacia (TBM), presenting with the softening of the walls of trachea and bronchi, can cause respiration problems. Despite the importance of TBM, data on its prevalence and related factors are limited. In the current study, the prevalence and predictive factors of this illness were investigated.

Methods: This cross-sectional study was conducted on patients who were bronchoscopy candidates in the diagnostic department of pulmonary diseases in Afzalipour hospital in Kerman, Iran, from May 2017 to May 2018. First, all patients diagnosed with TBM were assessed based on their demographic variables, spirometry indices, anthracofibrosis and TBM severity. TBM was defined as a $50 \%$ or higher decrease in the diameter of the main tracheal and bronchial walls on expiration. These patients constituted the case group. Other patients for whom the bronchoscopy findings were not in concordance with TBM were selected through convenience sampling as control group to equal the number of patients in the case group. Data were analyzed using SPSS version 23.

Results: In this study, $132(9.38 \%, 95 \%$ Cl: 8-11) of the total 1406 cases who underwent bronchoscopy had tracheomalacia. Also, 22 patients $(16.66 \%)$ had bronchomalacia, at the same time. Based on the multivariable logistic test results, age $(P=0.03,95 \%$ $\mathrm{Cl}: 1.00-1.04, \mathrm{OR}=1.02)$ and having anthracofibrosis $(P<0.0001,95 \% \mathrm{Cl}: 1.26-4.68, \mathrm{OR}=2.43)$ were identified as predictive factors for tracheomalacia.

Conclusion: The findings of the present study suggest that the presence of anthracotic plaques can be considered as a possible predictive factor for TBM.

Keywords: Anthracofibrosis, Anthracosis, Bronchoscopy, Iran, Tracheobronchomalacia

Cite this article as: Samareh Fekri M, Hashemi Bajgani SM, Shafahi A, Shafiepour M, Yazdani R, Ahmadpour Baghdadabad MH.

Bronchial anthracofibrosis and tracheobronchomalacia. Arch Iran Med. 2021;24(6):467-472. doi: 10.34172/aim.2021.67
\end{abstract}

Received: May 13, 2020, Accepted: September 8, 2020, ePublished: June 1, 2021

\section{Introduction}

Tracheobronchomalacia (TBM) is an illness presenting with the softening and flaccidity of the walls of trachea and bronchi, indicating the weakness of the walls of these organs. ${ }^{1}$ The weakness of the respiratory tract walls can increase the risk of its collapse, which will, in turn, lead to respiration problems. This condition is especially exacerbated in exhalation. ${ }^{2-6}$

TBM is classified into two types of primary and secondary. In the former case, the problem begins from birth and results from malformation or unnatural consistency of tracheal rings. ${ }^{7,8}$ The second form is associated with several factors including chronic inflammatory of respiratory tract such as tracheobronchitis, smoking, chronic obstructive pulmonary disease, asthma, and connective tissue disorders in some studies. Furthermore, some mechanical factors, such as external pressures resulting from vascular problems, tumors, trauma, and previous intubation have also been mentioned as secondary causes. However, the factors associated with the development of this disease are not thoroughly known. ${ }^{9-11}$

The weakness of the walls of trachea and bronchi can lead to dynamic obstruction of the respiratory tract. It can also cause severe conditions such as expiratory stridor, severe cough, inhaled bronchodilator and corticosteroid- resistant wheezing, recurrent lower respiratory tract infections, and respiratory failure. ${ }^{12}$ The symptoms of this illness are nonexclusive, and are often misinterpreted as treatment-resistant asthma, leading to an increase in complications of treatment in patients. ${ }^{10}$ Eventually, $7 \%$ of patients with the severe and diffuse type of this disease might need mechanical ventilation due to respiratory failure. ${ }^{12}$ Stridor and hypoxia emerge in severe cases, leading to an $80 \%$ mortality rate if left untreated. In this regard, misdiagnosis as asthma and other respiratory diseases might delay the diagnosis, and lead to more deaths in these patients. ${ }^{13,14}$

In order to diagnose this illness, various methods such as simple pulmonary radiography, dynamic pulmonary CT scan, pulmonary function tests, and fluoroscopy for examining the dynamic function of respiratory tracts are suggested. However, the standard diagnostic method is fiberoptic bronchoscopy. $1,6,15,16$

The exact prevalence of this illness is not known, and the number of studies which have reported it has been on the increase lately. ${ }^{1,11,17}$ In some studies, conducted in general populations, this disease has been reported in $1 \%$ to $10 \%$ of bronchoscopies and in more than $20 \%$ of autopsies. In the study conducted by Ikeda et al, which focused on pulmonary patients who had undergone bronchoscopy 
for different reasons, the prevalence of tracheomalacia was reported to be $12.7 \% .^{18}$ Despite the importance of TBM, there has been a limited number of studies on its prevalence and related factors. ${ }^{19}$ In the present study, the prevalence and predictive factors of this illness are examined in patients who visited the bronchoscopy department of Afzalipour hospital in Kerman, Iran (Pulmonary Diseases Referral Center) from May 2017 to May 2018.

\section{Materials and Methods Subject and Setting}

This cross-sectional study was conducted from May 2017 to May 2018 on patients who were bronchoscopy candidates in the bronchoscopy department of Afzalipour hospital, in Kerman, Iran (Pulmonary Diseases Referral Center). All patients who were candidates for bronchoscopy for diagnosis of their diseases and referred to the bronchoscopy ward in the mentioned time interval were included in this study. Since history of surgeries on upper respiratory tracts and tracheostomy have been mentioned as causes of TBM in previous studies, these patients were excluded from the present study. Moreover, all the patients who could not tolerate bronchoscopy due to cardiovascular or respiratory impairments or did not consent to bronchoscopy were excluded from the study.

\section{Patients and Sampling Method}

TBM was defined as a $50 \%$ or higher decrease in the diameter of the main tracheal and bronchial walls on expiration. Based on the severity of collapse, the patients were divided into three groups, namely mild (50\%-75\% collapse), moderate $(76 \%-90 \%$ collapse), and severe (91\%-100\% collapse). ${ }^{15}$ These patients constituted the case group. Other patients for whom the bronchoscopy findings were not in concordance with TBM were selected through convenience sampling as control group to equal the number of patients in the case group. Thus, on the same day when one patient was diagnosed with TBM, we selected another patient without TBM as control for whom the bronchoscopy findings were not in concordance with TBM.

\section{Bronchoscopy Procedure}

All patients were under cardiovascular monitoring while receiving oxygen and Lidocaine $2 \%$ for local anesthesia, and underwent bronchoscopy using a fiberoptic bronchoscope (Pentax K700 Series) made in Japan. All bronchoscopies were performed by pulmonologists and the diagnosis of TBM and anthracnosis was based on definitions.

\section{Data Collection and Outcome}

A checklist was used for data collection. This form consisted of three parts. For quality checking (reliability), the pulmonologists reviewed the checklist and after corrections, the checklist was approved. The first part included bronchoscopy findings including positive or negative TBM and anthracofibrosis in which black plaques accompanied by deformity in respiratory tracts were simultaneously recorded as anthracofibrosis. ${ }^{20}$ The patients' demographic and clinical information such as age, sex, smoking and opium use, history of baking and working in mines, using corticosteroid drugs and history of intubation were recorded in the second part of the checklist. In the third part of the checklist, spirometry findings were recorded. The spirometry pattern, severity of spirometry and reversibility of airway are presented in Table 1. All checklists were completed by the corresponding author after bronchoscopy in the diagnostic department of pulmonary diseases in Afzalipour hospital.

\section{Statistical Analysis}

In this study, the data were described using descriptive statistical measures such as mean \pm Standard Deviation (SD), frequency, and 95\% confidence interval. To compare the demographic and clinical characteristics of patients with spirometry pattern, severity of spirometry, and reversibility, univariate logistic regression models were used. Finally, to determine the predictors of TBM, a multivariate logistic regression model was performed. For running this model, all variables with $\mathrm{P}$-values less than 0.2 were included. A backward LR elimination method was also utilized and in the last step, variables with $P$ values less than 0.05 were considered as predictors. All

Table 1. Spirometry Pattern and Severity of Spirometry and Reversibility

\begin{tabular}{|c|c|c|c|c|}
\hline \multicolumn{2}{|c|}{ Variables } & FEV1 & FVC & FEV1/FVC \\
\hline \multirow{3}{*}{ Spirometry pattern } & Normal & $>80 \%$ predicted & \multirow{3}{*}{$\begin{array}{c}>80 \% \text { predicted } \\
<80 \% \text { of the predicted } \\
\text { normal } \\
<80 \% \text { of the predicted } \\
\text { normal }\end{array}$} & $>0.7$ \\
\hline & Obstructive & $<80 \%$ of the predicted normal & & $<0.7$ \\
\hline & Restrictive & $<80 \%$ of the predicted normal & & $>0.7$ \\
\hline \multirow{3}{*}{ Severity of spirometry } & Mild & $\geq 80 \%$ & $\geq 80 \%$ & - \\
\hline & Moderate & $50-80 \%$ & $50-80 \%$ & - \\
\hline & Severe and very severe & $<50$ & $<50$ & - \\
\hline \multirow{2}{*}{ Reversibility } & Negative & - & - & - \\
\hline & Positive $^{*}$ & $>12 \%$ and $200 \mathrm{~mL}$ & - & - \\
\hline
\end{tabular}

FEV1, forced expiratory volume in one second; FVC, forced vital capacity.

*The measurement of FEV1 measured after applying 2 puffs of salbutamol inhaler (21). 
statistical analyses were performed using SPSS version 23 and the significance level was considered 0.05 in all twotailed tests.

\section{Results}

In this study, $132(9.38 \%, 95 \%$ CI: $8-11)$ out of the total 1406 patients who went through bronchoscopy had tracheomalacia. Also, 22 patients (16.66\%) suffered from bronchomalacia. Patients with tracheomalacia were divided into three groups: mild (55 patients, $41.66 \%$ ), moderate (49 patients, $37.12 \%$ ), and severe (28 patients, $21.21 \%$ ). The mean age of the participants in the study (the second phase) was 62.11 14.1 years (ranging from 23 to 93). Men comprised more than half of the population (146 patients, 55.3\%). While less than half of the patients reported having a history of smoking (112 patients, 42.4\%), narcotics users formed 52.3\% (138 patients) of the population. Based on the findings, less than a quarter of the patients had worked in mines (30 patients, $11.4 \%$ ), while more than $30 \%$ (91 patients, $34.5 \%$ ) had a history of baking bread (Table 2).

Table 2. Assessment of the Relation between Contextual and Clinical Variables in the Selected Groups

\begin{tabular}{|c|c|c|c|c|}
\hline \multicolumn{2}{|c|}{ Variables } & Total & $\begin{array}{c}\text { Tracheomalacia } \\
\text { patients } \\
(n=132)\end{array}$ & $\begin{array}{l}\text { Controls } \\
(n=132)\end{array}$ \\
\hline \multicolumn{2}{|c|}{ Age $($ mean $\pm \mathrm{SD})$} & 264 & $65.8914 .5 \pm$ & $58.3312 .7 \pm$ \\
\hline \multirow{2}{*}{ Gender } & Male & 146 & $64(4.8)$ & $82(56.2)$ \\
\hline & Female & 118 & $68(57.6)$ & $50(42.4)$ \\
\hline \multirow{2}{*}{ Smoking } & Negative & 152 & $82(53.9)$ & $70(46.1)$ \\
\hline & Positive & 112 & $50(44.6)$ & $62(55.4)$ \\
\hline \multirow{2}{*}{$\begin{array}{l}\text { Opium } \\
\text { addiction }\end{array}$} & Negative & 126 & 65 (51.6) & $61(48.4)$ \\
\hline & Positive & 138 & 67 (48.6) & $71(51.4)$ \\
\hline \multirow{2}{*}{$\begin{array}{l}\text { Corticosteroid } \\
\text { use }\end{array}$} & Negative & 193 & $95(49.2)$ & $98(50.8)$ \\
\hline & Positive & 71 & $37(52.1)$ & $34(47.9)$ \\
\hline \multirow{2}{*}{ Mine working } & Negative & 234 & $115(49.1)$ & $119(50.9)$ \\
\hline & Positive & 30 & $17(56.7)$ & $13(43.3)$ \\
\hline \multirow{2}{*}{ Baking history } & Negative & 173 & $72(41.6)$ & $101(58.4)$ \\
\hline & Positive & 91 & $60(65.9)$ & $31(34.1)$ \\
\hline \multirow{2}{*}{$\begin{array}{l}\text { Intubation } \\
\text { history }\end{array}$} & Negative & 248 & $126(50.8)$ & $122(49.2)$ \\
\hline & Positive & 16 & $6(37.5)$ & $10(62.5)$ \\
\hline \multirow{3}{*}{$\begin{array}{l}\text { Spirometry } \\
\text { indices }\end{array}$} & Normal & 49 & $10(20.4)$ & $39(79.6)$ \\
\hline & Obstructive & 186 & $99(53.2)$ & $87(46.8)$ \\
\hline & Restrictive & 29 & $23(79.3)$ & $6(20.7)$ \\
\hline \multirow{4}{*}{$\begin{array}{l}\text { Severity of } \\
\text { spirometry }\end{array}$} & Mild & 55 & $10(18.2)$ & $45(81.8)$ \\
\hline & Moderate & 87 & $55(63.2)$ & $32(36.8)$ \\
\hline & Severe & 76 & $46(60.5)$ & $30(39.5)$ \\
\hline & Very severe & 46 & $21(45.7)$ & $25(54.3)$ \\
\hline \multirow{2}{*}{ Reversibility } & Negative & 51 & $33(64.7)$ & $18(35.3)$ \\
\hline & Positive & 135 & $66(48.9)$ & $69(51.1)$ \\
\hline \multirow{2}{*}{ Anthracofibrosis } & Negative & 186 & 74 (39.8) & $112(60.2)$ \\
\hline & Positive & 78 & $58(74.4)$ & $20(25.6)$ \\
\hline \multirow{2}{*}{ Bronchomalacia } & Negative & 242 & $110(45.5)$ & $132(54.5)$ \\
\hline & Positive & 22 & 22 (100) & - \\
\hline
\end{tabular}

Reversibility was only checked in patients with obstructive spirometry pattern.
According to the univariate logistic model results, the study population was different in terms of age $(P<0.0001)$, gender $(P<0.02)$, history of baking bread $(P<0.0001)$, spirometry indices $(P<0.0001)$, and having pulmonary anthracofibrosis, in such a way that older patients compared to younger ones $(P<0.0001,95 \% \mathrm{CI}$ : $1.02-1.06, \mathrm{OR}=1.04)$, women compared to men $(P=$ $0.02,95 \%$ CI: $1.06-2.84, \mathrm{OR}=1.74$ ), patients who had a history of baking bread compared to those who did not $(P<0.0001,95 \% \mathrm{CI}: 1.60-4.60, \mathrm{OR}=2.71)$, patients who, based on spirometry indices, had obstructive patterns $(\mathrm{P}<0.0001,95 \% \mathrm{CI}: 2.09-9.41, \mathrm{OR}=4.43)$ and restrictive patterns $(P<0.0001,95 \% \mathrm{CI}: 4.80-46.54, \mathrm{OR}=14.94)$ compared to normal patients, patients who, based on the severity of spirometry indices, were in the mild group $(P<0.0001,95 \%$ CI: 3.02-15.74, OR = 7.73), the moderate group $(P<0.0001,95 \% \mathrm{CI}: 3.02-15.74, \mathrm{OR}=6.90)$ and the severe group $(P<0.0001,95 \% \mathrm{CI}: 1.54-9.27, \mathrm{OR}=$ 3.78) compared to normal patients, and patients with anthracofibrosis compared to those who did not have it $(P<0.0001,95 \%$ CI: $1.26-4.68$, OR $=4.38)$ had a higher probability of developing tracheomalacia (Table 3 ).

Table 3. The Results of the Univariate Logistic Regression Model of for Determining the Predictive Factors of Tracheomalacia

\begin{tabular}{|c|c|c|c|}
\hline Variable & & $\begin{array}{l}\text { Crude Odds Ratio } \\
\text { (95\% Confidence }\end{array}$ & P value \\
\hline Age & & $1.04(1.02,1.06)$ & 0.001 \\
\hline & Male & 1 & \\
\hline cender & Female & $1.74(1.06,2.84)$ & 0.02 \\
\hline Smoking & Negative & 1 & 012 \\
\hline & positive & $0.68(0.42,1.12)$ & 0.15 \\
\hline & Negative & 1 & 060 \\
\hline Opiumin duarction & positive & $0.88(0.54,1.43)$ & 0.02 \\
\hline Corticesteroid uce & Negative & 1 & 0,7 \\
\hline comicosterica use & positive & $1.12(0.65,1.93)$ & 0.07 \\
\hline Mine working & Negative & 1 & 0.42 \\
\hline & positive & $1.35(0.62,2.91)$ & \\
\hline Raking history & Negative & 1 & 001 \\
\hline Daking mistory & positive & $2.71(1.60,4.60)$ & 0.001 \\
\hline Intubution bictor & Negative & 1 & 020 政 \\
\hline mutudarom mistory & positive & $0.58(0.20,1.64)$ & 0.30 \\
\hline & normal & 1 & \\
\hline Spirometry indices & Obstructive & $4.43(2.09,9.41)$ & 0.001 \\
\hline & Restrictive & $14.95(4.80,46.54)$ & \\
\hline & Normal & 1 & \\
\hline & Mild & $7.73(3.43,17.42)$ & \\
\hline spirometry & Moderate & $6.90(3.02,15.74)$ & 0.001 \\
\hline & $\begin{array}{l}\text { Severe and } \\
\text { very severe }\end{array}$ & $3.78(1.54,9.27)$ & \\
\hline reyersihility & Negative & 1 & 005 \\
\hline reversiominy & positive & $0.52(0.26,1.01)$ & 0.03 \\
\hline Anthrosof $\mathrm{s}$ & Negative & 1 & $0 \Omega 0$ \\
\hline & positive & $4.38(2.44,7.89)$ & \\
\hline
\end{tabular}


Finally, according to the multivariable logistic regression model, age $(P=0.03,95 \% \mathrm{CI}: 1.00-1.04, \mathrm{OR}=1.02)$ and having anthracofibrosis $(P<0.0001,95 \% \mathrm{CI}: 1.26-4.68$, $\mathrm{OR}=2.43)$ were identified as predictive factors for tracheomalacia (Table 4). Furthermore, based on the data of Table 5, although more than half of the patients with tracheomalacia were in favorable conditions regarding the reversibility status, there was no significant relation between having tracheomalacia and reversibility of the respiratory tract $(P=0.65)$

\section{Discussion}

In this study, $132(9.38 \%, 95 \%$ CI: $8-11)$ out of the total 1406 patients who went through bronchoscopy, had tracheomalacia. Age and spirometry indices were identified as predictors of tracheomalacia. In this study, bronchial anthracofibrosis was also introduced as a predictor for TBM for the first time.

The prevalence of TBM is not exactly known. Due to the expansion of noninvasive diagnostic methods, as well as more frequent patient evaluations for diagnosing TBM, the reports show a higher prevalence of this illness, and based on the population and method of each study, different prevalence rates, from $4 \%$ to $23 \%$, have been reported. ${ }^{4}$ In a study conducted by Jokinen et al, the prevalence of TBM was reported to be nearly $4.5 \% .{ }^{22}$ In another study, the prevalence of TBM among patients with respiratory complaints was $13.5 \% .{ }^{18}$ In a study, in which patients were examined for chronic cough, bronchoscopy revealed a $14.1 \%$ prevalence of an over 50 percent collapse in the trachea and main bronchi. ${ }^{23}$ In a study conducted by Jokinen et al., the prevalence of TBM in patients with chronic bronchitis was approximately $23 \% .{ }^{24}$ Based on the different statistics in different studies, we can say that the reason for the disparity may lie in the difference between populations and diagnostic methods used in these studies.

Table 4. The Results of the Multivariate Logistic Regression Model of for Determining the Predictive Factors of Tracheomalacia.

\begin{tabular}{|c|c|c|c|}
\hline \multicolumn{2}{|c|}{ Variables } & \multirow{2}{*}{$\begin{array}{c}\begin{array}{c}\text { Adjusted Odds Ratio } \\
\text { (95\% Confidence } \\
\text { Interval) }\end{array} \\
1.02\end{array}$} & \multirow{2}{*}{$\begin{array}{c}\boldsymbol{P} \text { value } \\
0.03\end{array}$} \\
\hline Age & & & \\
\hline \multirow{2}{*}{ Baking history } & Negative & 1 & \multirow{2}{*}{0.06} \\
\hline & Positive & $1.72(0.95,3.10)$ & \\
\hline \multirow{3}{*}{ Spirometry indices } & Normal & 1 & \multirow{3}{*}{0.001} \\
\hline & Obstructive & $2.56(1.13,5.80)$ & \\
\hline & Restrictive & $9.11(2.77,29.87)$ & \\
\hline \multirow{2}{*}{ Anthracofibrosis } & Negative & 1 & \multirow{2}{*}{0.001} \\
\hline & Positive & $2.43(1.26,4.68)$ & \\
\hline
\end{tabular}

Table 5. Comparison of Airway Irreversibility Based on Tracheomalacia Diagnosis.

\begin{tabular}{lccc}
\hline & Reversible & Irreversible & $\boldsymbol{P}$ value \\
\hline With Tracheomalacia & $73(55.3)$ & $59(44.7)$ & \\
Without Tracheomalacia & $86(57.1)$ & $59(42.9)$ & 0.65 \\
\hline
\end{tabular}

In a study conducted in 2013 by Dal Negro et al, ${ }^{12}$ the prevalence of TBM was evaluated by bronchoscopy in 202 patients with asthma and 62 healthy, non-smoking people. The prevalence of TBM was $1.6 \%$ and $9.4 \%$ in healthy people and in patients with asthma, respectively. The prevalence of TBM had a positive and significant relation with the severity of obstruction. In our study, the prevalence of TBM was 9.38\%, which was similar to the asthma patients in the study by Dal Negro et al. This similarity can be a result of the high prevalence of obstructive pattern in the population of our study. Also, in our study, the prevalence of TBM had a significant relation with the obstructive pattern and obstructive severity, as well as the restrictive pattern.

In a study conducted by Majid et al, nearly $17 \%$ of the patients diagnosed with TBM had normal pulmonary function test results, and no significant relation existed between TBM and obstructive or restrictive patterns. ${ }^{25}$ In a study by Loring et al., no significant relation was observed between the severity of obstruction, which was measured based on the forced expiratory volume in one second (FEV1) ratio, and central respiratory tract collapse. ${ }^{26}$

However, in the above-mentioned studies, only patients with TBM symptoms were examined while in our study, all bronchoscopy candidates, regardless of the reason, were examined for TBM, and those who were diagnosed underwent pulmonary function tests.

This illness is prevalent in patients with common respiratory diseases, such as asthma or chronic obstructive pulmonary disease (COPD). ${ }^{1,27}$ Kandaswamy and Balasubramanian, in a study conducted in 2009, analyzed the relation between adult tracheomalacia and COPD. They stated that since the prevalence of COPD is increasing throughout the world, finding a relation between TBM and COPD is extremely critical. Analyzing the relation between TBM and COPD, they claimed that TBM can be considered as a form of COPD. ${ }^{28,29}$

In our study, a significant relation was observed between obstructive and restrictive spirometry patterns and TBM. Also, based on the findings of the study, although more than half of the patients with tracheomalacia were in favorable conditions regarding their reversibility status, no significant relation was found between tracheomalacia and reversibility of the respiratory tract. Anthracofibrosis is defined as a decrease in the diameter of bronchi accompanied by black pigment, which is diagnosed by bronchoscopy. ${ }^{30}$ It is stated that the reactions in respiratory tracts caused by this condition can lead to fibrotic changes and the narrowing of bronchi. ${ }^{31}$ This condition can also be accompanied by obstruction of bronchi. ${ }^{32,33}$

The causes of anthracofibrosis are not explained thoroughly yet, but being exposed to smoke, fossil fuels, organic particles, and tuberculosis have been mentioned as some possible causes. In fact, anthracofibrosis was previously considered as a symptom of an old or new tuberculosis infection. ${ }^{33,34}$ However, nowadays, new evidence proves that intense exposure to biomass fuels 
(any material with herbal or animal origin which is burnt in order to produce energy) are the main cause of anthracofibrosis..$^{20,34}$ Also, we can say that anthracofibrosis is a kind of COPD which is related to fossil fuels, and that radiologic and bronchoscopic evidence suggests that anthracofibrosis is the reaction of the lung to fossil fuels. ${ }^{34}$

So far, no study has addressed the association between anthracofibrosis and TBM. In any case, in our study, anthracofibrosis was suggested as a predictive factor for TBM.

This study had several limitations. First, we assessed TBM among patients with pulmonary diseases. Due to some ethical considerations, we could not perform bronchoscopy for the general population. Therefore, the results of our study could not be generalized to the whole population. It would have been better if the bronchoscopy findings were assessed along with chest CT-scan findings, but we did not perform this diagnostic evaluation due to radiation exposure which was not necessary for all patients. The second limitation was using convenience sampling for selecting the control group due to its effect on external validity of the study. It was better to use random sampling, but we did not perform this method due to some restrictions.

In conclusion, considering the significance of the relation between baking bread and being female, and TBM, we can state that due to the fact that use of wood in baking bread is extremely common among the women of the area under study, it can cause anthracotic pigments in the respiratory tract and lungs, and by causing inflammation, predispose them to TBM. The findings of the present study suggest that the presence of anthracotic plaques can be considered as a possible predictive factor for TBM.

\section{Authors' Contribution}

MSF: The header of the study and the whole idea was hers. MHAB: The information gathering, writing and editing. SMHB, AS, MS and RY performed the procedure and fill up the check lists.

\section{Conflict of Interest Disclosures}

The authors declare that they have no conflict of interest.

\section{Ethical Statement}

The protocol of the present study was reviewed and approved by the Ethics Committee of Kerman University of Medical Sciences (code of ethics: IR.KMU.AH.REC.1396.2181). Informed consent was taken from all participants before the procedure.

\section{References}

1. Buitrago DH, Wilson JL, Parikh M, Majid A, Gangadharan SP. Current concepts in severe adult tracheobronchomalacia: evaluation and treatment. J Thorac Dis. 2017;9(1):E57-E66. doi: 10.21037/jtd.2017.01.13.

2. Medscape. Schwartz DS, Sharma S. Tracheomalacia. 2020. Available from: https://emedicine.medscape.com/ article/426003-overview.

3. National Institutes of Health. National Library of Medicine. Tracheomalacia - congenital. Available from: https:// medlineplus.gov/ency/article/001084.htm.

4. Choo EM, Seaman JC, Musani AI. Tracheomalacia/ Tracheobronchomalacia and hyperdynamic airway collapse. Immunol Allergy Clin North Am. 2013;33(1):2334. doi: 10.1016/j.iac.2012.10.005.

5. Ameli J, Ghanei M, Aslani J', Karami G, Ghoddousi $\mathrm{K}$, Kachuee $\mathrm{H}$;, et al. Polysomnography of 31 mustard gas exposed veterans with complaint of respiratory sleep problem in Baqiyatallah (as) hospital. J Mil Med. 2007;9(1):7-14. [Persian].

6. Ullmann N, Secinaro A, Menchini L, Caggiano S, Verrillo E, Santangelo TP, et al. Dynamic expiratory CT: an effective non-invasive diagnostic exam for fragile children with suspected tracheo-bronchomalacia. Pediatr Pulmonol. 2018;53(1):73-80. doi: 10.1002/ppul.23831.

7. Hasegawa I, Boiselle PM, Raptopoulos V, Hatabu H. Tracheomalacia incidentally detected on CT pulmonary angiography of patients with suspected pulmonary embolism. AJR Am J Roentgenol. 2003;181(6):1505-9. doi: 10.2214/ajr.181.6.1811505.

8. Cedars Sinai, Health Library. Tracheomalacia. Available from: https://www.cedars-sinai.org/health-library/ diseases-and-conditions/t/tracheomalacia.html.

9. Gilkeson RC, Ciancibello LM, Hejal RB, Montenegro HD, Lange P. Tracheobronchomalacia: dynamic airway evaluation with multidetector CT. AJR Am J Roentgenol. 2001;176(1):205-10. doi: 10.2214/ajr.176.1.1760205.

10. Uyar M, Sanli M, Kervancioglu S, Taskin-Dogan B, Bakir $\mathrm{K}$, Dikensoy O. Tracheobronchomalacia as a rare cause of chronic dyspnea in adults. Med Princ Pract. 2017;26(2):17981. doi: 10.1159/000455858.

11. Murgu SD, Colt HG. Recognizing tracheobronchomalacia. J Respir Dis. 2006;6(8):327-35.

12. Dal Negro RW, Tognella S, Guerriero M, Micheletto C. Prevalence of tracheobronchomalacia and excessive dynamic airway collapse in bronchial asthma of different severity. Multidiscip Respir Med. 2013;8(1):32. doi: 10.1186/2049-6958-8-32.

13. Jiang AG, Gao XY, Lu HY. Diagnosis and management of an elderly patient with severe tracheomalacia: a case report and review of the literature. Exp Ther Med. 2013;6(3):7658. doi: 10.3892/etm.2013.1195.

14. Bazrafshan E, Hasanpoor MR, Yal N. Aortopexy for treatment of severe tracheomalacia, report of three cases. Iran J Otorhinolaryngol. 2006;18(2):93-8.

15. Majid A, Gaurav K, Sanchez JM, Berger RL, Folch E, Fernandez-Bussy S, et al. Evaluation of tracheobronchomalacia by dynamic flexible bronchoscopy. A pilot study. Ann Am Thorac Soc. 2014;11(6):951-5. doi: 10.1513/AnnalsATS.201312-435BC.

16. Ernst A, Odell DD, Michaud G, Majid A, Herth FFJ, Gangadharan SP. Central airway stabilization for tracheobronchomalacia improves quality of life in patients with COPD. Chest. 2011;140(5):1162-8. doi: 10.1378/ chest.10-3051.

17. Kandaswamy C, Bird G, Gill N, Math E, Vempilly JJ. Severe tracheomalacia in the ICU: identification of diagnostic criteria and risk factor analysis from a case control study. Respir Care. 2013;58(2):340-7. doi: 10.4187/respcare.01866.

18. Ikeda S, Hanawa T, Konishi T, Adachi M, Sawai S, Chiba $\mathrm{W}$, et al. [Diagnosis, incidence, clinicopathology and surgical treatment of acquired tracheobronchomalacia]. 
Nihon Kyobu Shikkan Gakkai Zasshi. 1992;30(6):1028-35. [Japanese].

19. Agarwal A, Mishra AK, Gupta SK, Arshad F, Agarwal A, Tripathi $M$, et al. High incidence of tracheomalacia in longstanding goiters: experience from an endemic goiter region. World J Surg. 2007;31(4):832-7. doi: 10.1007/ s00268-006-0565-8.

20. Gupta A, Shah A. Bronchial anthracofibrosis: an emerging pulmonary disease due to biomass fuel exposure. Int J Tuberc Lung Dis. 2011;15(5):602-12. doi: 10.5588/ ijtld.10.0308.

21. Global Initiative for Asthma (GINA). Diagnosis and initial treatment of asthma, COPD and asthma-COPD overlap. 2017. Available from: https://ginasthma.org/wp-content/ uploads/2019/11/GINA-GOLD-2017-overlap-pocketguide-wms-2017-ACO.pdf.

22. Jokinen K, Palva T, Sutinen S, Nuutinen J. Acquired tracheobronchomalacia. Ann Clin Res. 1977;9(2):52-7.

23. Palombini BC, Villanova CA, Araújo E, Gastal OL, Alt DC, Stolz DP, et al. A pathogenic triad in chronic cough: asthma, postnasal drip syndrome, and gastroesophageal reflux disease. Chest. 1999;116(2):279-84. doi: 10.1378/ chest.116.2.279.

24. Jokinen K, Palva T, Nuutinen J. Chronic bronchitis. A bronchologic evaluation. ORL J Otorhinolaryngol Relat Spec. 1976;38(3):178-86. doi: 10.1159/000275273.

25. Majid A, Sosa AF, Ernst A, Feller-Kopman D, Folch E, Singh AK, et al. Pulmonary function and flow-volume loop patterns in patients with tracheobronchomalacia. Respir Care. 2013;58(9):1521-6. doi: 10.4187/respcare.02277.

26. Loring SH, O’Donnell C R, Feller-Kopman DJ, Ernst A.
Central airway mechanics and flow limitation in acquired tracheobronchomalacia. Chest. 2007;131(4):1118-24. doi: 10.1378/chest.06-2556.

27. de Mello RA, Magalhães A, Vilas-Boas AJ. Stridor and respiratory failure due to tracheobronchomalacia: case report and review of the literature. Sao Paulo Med J. 2012;130(1):61-4. doi: 10.1590/s1516-31802012000100011.

28. Kandaswamy C, Balasubramanian V. Review of adult tracheomalacia and its relationship with chronic obstructive pulmonary disease. Curr Opin Pulm Med. 2009;15(2):1139. doi: 10.1097/MCP.0b013e328321832d.

29. Campbell AH, Faulks LW. Expiratory air-flow pattern in tracheobronchial collapse. Am Rev Respir Dis. 1965;92(5):781-91. doi: 10.1164/arrd.1965.92.5.781.

30. Ahn HS, Hwang JH, Chang YW, Kim HJ, Kwon KH, Choi DL. Pictorial review of diffuse central airway diseases: focus on CT findings. Tuberc Respir Dis. 2011;70(1):10-20. doi: 10.4046/trd.2011.70.1.10.

31. Puchalski J. Tracheal and bronchial stenosis: etiologies, bronchoscopic interventions and outcomes. Pak J Chest Med. 2012;18(1):38-46.

32. Kim YJ, Jung CY, Shin HW, Lee BK. Biomass smoke induced bronchial anthracofibrosis: presenting features and clinical course. Respir Med. 2009;103(5):757-65. doi: 10.1016/j. rmed.2008.11.011.

33. Chung MP, Lee KS, Han J, Kim H, Rhee CH, Han YC, et al. Bronchial stenosis due to anthracofibrosis. Chest. 1998;113(2):344-50. doi: 10.1378/chest.113.2.344.

34. Assad NA, Kapoor V, Sood A. Biomass smoke exposure and chronic lung disease. Curr Opin Pulm Med. 2016;22(2):1507. doi: $10.1097 / \mathrm{mcp} .0000000000000246$. 